\title{
The mid-Pleistocene transition in the subtropical southwest Pacific
}

\author{
T. Russon, ${ }^{1}$ M. Elliot, ${ }^{1}$ A. Sadekov, ${ }^{1}$ G. Cabioch, ${ }^{2}$ T. Corrège, ${ }^{3}$ and P. De Deckker ${ }^{4}$ \\ Received 24 June 2010; revised 14 November 2010; accepted 28 December 2010; published 11 March 2011.
}

[1] Reconstructions of subtropical southwest Pacific climate variability over the Pleistocene were derived from coupled planktic foraminiferal $\delta^{18} \mathrm{O}-\mathrm{Mg} / \mathrm{Ca}$ measurements taken from a southern Coral Sea sediment core. A clear shift from $\sim 40 \mathrm{kyr}$ to $\sim 100 \mathrm{kyr}$ modes of reconstructed glacial-interglacial sea surface temperature (SST) variability is seen over the mid-Pleistocene transition, and these fluctuations are shown to have remained coherent with the orbital obliquity cycle across the transition. The likely origin of this strong obliquity signal in subtropical southwest Pacific SST is shown to be the southern high latitudes, and comparison with existing SST reconstructions from the equatorial Pacific is consistent with the communication of the signal occurring principally by greenhouse gas forcing. In contrast to the SST reconstruction, regional hydrological cycle variability (based on the calculated local component of $\delta^{18} \mathrm{O}_{\text {sw }}$ change) does not show significant coherence with obliquity after $\sim 1000 \mathrm{ka}$. The decoupling of the SST and hydrological cycle responses over the mid-Pleistocene transition allows constraints to be placed on the evolution and extent of orbitally paced fluctuations within the coupled low-latitude ocean-atmosphere system.

Citation: Russon, T., M. Elliot, A. Sadekov, G. Cabioch, T. Corrège, and P. De Deckker (2011), The mid-Pleistocene transition in the subtropical southwest Pacific, Paleoceanography, 26, PA1211, doi:10.1029/2010PA002019.

\section{Introduction}

[2] The observed patterns of variability in the Earth's climate system on the 10-100 kyr timescale are widely believed to be influenced by periodic variations in the orbital parameters of the Earth, which act to change the distribution of solar energy received at the surface [Hays et al., 1976; Imbrie et al., 1992, 1993; Milankovitch, 1948]. The dominant orbital periodicities are those of the precession cycle $(\sim 20 \mathrm{kyr})$, its modulation through eccentricity ( $\sim 100 \mathrm{kyr}$ and $\sim 400 \mathrm{kyr})$ and the obliquity cycle ( $40 \mathrm{kyr})$ [Laskar et al., 2004]. Across the Plio-Pleistocene, aspects of the climate system are observed to respond at all of these periods, but this response is in all cases at least somewhat nonlinear and active debate remains as to the extent to which the climate system is forced by and/ or phase locked to orbital variability at each period [Ashkenazy and Tziperman, 2004; Elkibbi and Rial, 2001; Ruddiman, 2003].

[3] Stacked records of benthic foraminiferal stable oxygen isotope ratios $\left(\delta^{18} \mathrm{O}_{\text {benthic }}\right)$, such as the LR04 stack [Lisiecki and Raymo, 2005], provide a first-order proxy, on timescales exceeding that of ocean overturning, for fluctuations in global ice volume. These records reveal that the planet has undergone significant "glacial-interglacial" cycles in ice volume on orbital (10-100 kyr) timescales across the Plio-

\footnotetext{
${ }^{1}$ School of GeoSciences, University of Edinburgh, Edinburgh, UK.

${ }^{2}$ IPSL/LOCEAN, UMR 7159 IRD/CNRS/UPMC/MNHN, Centre IRD d'Ile de France, Bondy, France.

${ }^{3}$ Université de Bordeaux, UMR 5805 EPOC, Talence, France.

${ }^{4}$ Research School of Earth Sciences, Australian National University, Canberra, ACT, Australia.

Copyright 2011 by the American Geophysical Union. 0883-8305/11/2010PA002019
}

Pleistocene. The direct effect of the combined orbital variations on mean annual insolation at $60^{\circ} \mathrm{N}$ across the Last Glacial Maximum (LGM) to Holocene transition is, however, small $\left(\sim 1 \mathrm{~W} / \mathrm{m}^{2}\right)$ compared to those arising from both continental ice volume changes $\left(\sim 12 \mathrm{~W} / \mathrm{m}^{2}\right)$ and greenhouse gas (principally $\left.\mathrm{CO}_{2}\right)$ variability $\left(\sim 2 \mathrm{~W} / \mathrm{m}^{2}\right)[$ Broccoli, 2000]. This implies that while the timing of the glacialinterglacial cycles may well be phase locked to the orbital cycles, feedback processes within the Earth system play a significant, even dominant role in the radiative forcing of the global climate response.

[4] The mid-Pleistocene transition (MPT), circa 500 $1200 \mathrm{ka}$ [Head and Gibbard, 2005], represented the last major change in the observed mode of glacial-interglacial ice volume variability, namely that from the " 40 kyr world" of the late Pliocene and early Pleistocene to the more asymmetric and higher amplitude cycles of the "100 kyr world" of the middle and late Pleistocene [Head and Gibbard, 2005; Imbrie et al., 1993; Mudelsee and Stattegger, 1997]. The transition occurred without any shift in the mode of orbital forcing, demonstrating that the climate response to orbital variations is nonlinear on the $>100 \mathrm{kyr}$ timescale and that threshold levels exist within one or more of the key processes within the Earth system that have acted to change the mode of response. Evaluating whether the additional source of nonlinearity that led to the emergence of the $\sim 100 \mathrm{kyr}$ mode resided in ice sheet dynamics [Bintanja and van de Wal, 2008; Clark and Pollard, 1998], the carbon cycle [Shackleton, 2000], or other processes, remains a key objective in paleoceanographic research.

[5] Proxy records of sea surface temperature (SST) from all latitudes and ocean basins also show a transition in the amplitude and dominant period of glacial-interglacial vari- 
ability across the MPT period [e.g., Crundwell et al., 2008; Liu et al., 2008; Marlow et al., 2000; Medina-Elizalde and Lea, 2005; Ruddiman et al., 1989]. However, SST reconstructions show much more spatial variability in the amplitude, timing and structure of glacial-interglacial variability than those of $\delta^{18} \mathrm{O}_{\text {benthic. This is a consequence of both }}$ the spatial variation in the radiative forcing and feedback factors that control SST and also of the advective effect of ocean circulation patterns. It also means that reconstructions of SST from different parts of the world have the potential to yield useful information about the relative importance of different orbital timescale climate feedback systems.

[6] In the case of the low-latitude (taken here as being $30^{\circ} \mathrm{N}$ to $30^{\circ} \mathrm{S}$ ) Pacific, where ice sheet fluctuations do not directly affect the radiation budget, it has been proposed that greenhouse gas forcing has exerted the dominant control on glacial-interglacial SST variability across the MPT [Medina-Elizalde and Lea, 2005] and as far back as the late Pliocene [Medina-Elizalde and Lea, 2010]. If this hypothesis is correct then it would follow that reconstructed lowlatitude SST variability may provide an indirect guide to the carbon cycle response to orbital forcing during the middle and early Pleistocene. Even within the low latitudes the observed amplitude of middle/late Pleistocene glacialinterglacial SST variability is not, however, spatially uniform as would result from forcing by greenhouse gas variability alone. This heterogeneity arises principally from ocean circulation patterns and their effect on meridional heat transport. In particular, the low-latitude ventilation of upperocean (taken here as being thermocline and intermediate depth) waters of primarily southern hemisphere origin contributes around half of the total LGM SST cooling seen in the low-latitude Pacific in coupled ocean-atmosphere model studies [Liu et al., 2002].

[7] Both theoretical studies [Philander and Fedorov, 2003] and proxy reconstructions [Beaufort et al., 2001] have suggested that, during at least the middle/late Pleistocene, the Pacific thermocline was generally shallower during glacial (as opposed to interglacial) periods, implying systematic orbital timescale changes in upper-ocean ventilation and hence, the direct advection of the high-latitude climate response into the low-latitude Pacific. Changes in the tilt of the low-latitude Pacific thermocline are closely related on interannual timescales to the coupled ocean-atmosphere El Niño-Southern Oscillation (ENSO) phenomenon, which has a significant effect on both the mean annual SST distribution and the hydrological cycle across the low-latitude Pacific [Sarachik and Cane, 2010].

[8] Modeling studies suggest that the dominant orbital influence on the dynamics of the ENSO system in a strict sense is the orbital precession cycle, through its effect on seasonal low-latitude insolation budgets [Clement et al., 1999]. However, it has also been proposed that both millennial [Stott et al., 2002] and orbital [Koutavas et al., 2002; Philander and Fedorov, 2003] timescale responses of the low-latitude ocean-climate system can be characterized as resembling so-called "super-ENSO" states. In these scenarios, it is possible that the low-latitude ocean-atmosphere system may, through meridional heat-moisture fluxes, have played a substantial role in modulating global climate on glacial-interglacial timescales.

[9] The MPT may have represented either an increase in the nonlinearity of the climate system response to obliquity forcing [Huybers, 2007; Liu et al., 2008] or an enhanced sensitivity to precession and/or eccentricity [Imbrie et al., 1993; Raymo, 1997]. It is therefore also possible that the amplitude and character of any orbital timescale superENSO fluctuations may have changed over the MPT. Any such changes would at least challenge the reliability of the middle/late Pleistocene orbital timescale low-latitude SST to carbon cycle variability relationship as a guide to conditions in the $40 \mathrm{kyr}$ world.

[10] This paper presents reconstructions of SST (as proxied by planktic foraminiferal $\mathrm{Mg} / \mathrm{Ca}$ ) and hydrological cycle variability (as proxied by the extraction of the "local" component of $\delta^{18} \mathrm{O}_{\mathrm{sw}}$ variability, calculated in turn from coupled measurements of planktic foraminiferal $\delta^{18} \mathrm{O}-\mathrm{Mg} /$ $\mathrm{Ca}$ ) at suborbital temporal resolution and spanning the past $1500 \mathrm{kyr}$, from sediment core MD06-3018 in the southern Coral Sea, subtropical southwest Pacific. The Coral Sea is significantly affected by ENSO related fluctuations in both SST (Figure 1) and precipitation on the interannual timescale [Delcroix and Lenormand, 1997] and coupled reconstructions of SST and hydrological cycle variability from the region therefore provide a method for evaluating the existence and importance of orbital timescale super-ENSO variability. The simplest formulation of such an approach is that strong covariance in the response seen in the SST and hydrological cycle proxies would suggest a dominant superENSO control on both variables, whereas strong decoupling would imply different forcing mechanisms. The $\mathrm{Mg} / \mathrm{Ca}-$ derived MD06-3018 SST reconstruction has already been used to demonstrate the long-term ( $>100 \mathrm{kyr}$ timescale) stability of SST in the southern Coral Sea over the past $1500 \mathrm{kyr}$ [Russon et al., 2010]. The record is now reassessed, in comparison with the coupled $\delta^{18} \mathrm{O}_{\text {planktic }}$ record, in terms of 10-100 kyr timescale variability in order to constrain the forcing mechanisms of orbital timescale variability in subtropical southwest Pacific climate across the MPT.

\section{Materials and Methods}

\subsection{Sediment Core MD06-3018}

[11] Sediment core MD06-3018 was recovered from $2470 \mathrm{~m}$ water depth in the eastern New Caledonia Trough, southern Coral Sea, subtropical southwest Pacific $\left(23^{\circ} 00^{\prime} \mathrm{S}\right.$, $166^{\circ} 09^{\prime} \mathrm{E}$, Figure 1). The core site is $\sim 60 \mathrm{~km}$ from the New Caledonia Barrier Reef but is located on a broad bathymetric high that generally shelters the site from significant downslope transport of shallow-water material. There is some wind-driven upwelling of waters from $\sim 100 \mathrm{~m}$ depth along the New Caledonia reef front, but the effect of this phenomenon is limited principally to a narrow $(\sim 10 \mathrm{~km})$ band parallel to the western reef front and to timescales of days to weeks [Alory et al., 2006; Hénin and Cresswell, 2005].

[12] The core is $24.5 \mathrm{~m}$ long and composed of homogenous calcareous ooze dominated in the $>150 \mu \mathrm{m}$ size fraction by planktic foraminifera of a tropical/subtropical assemblage. The core site of MD06-3018 is located more than $600 \mathrm{~m}$ 


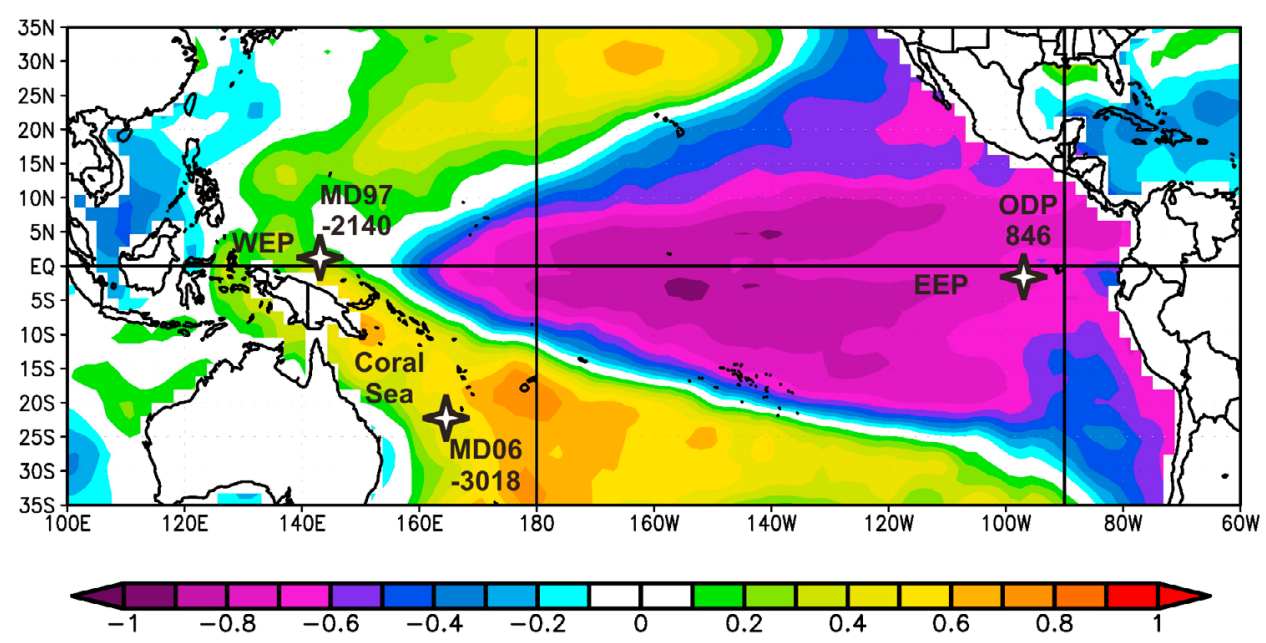

Figure 1. Contour map of the correlation index between mean annual SST and the Southern Oscillation Index within the low-latitude Pacific over the interval 1948-2000, with the location of the core sites discussed in the text shown. Similar index values at any two locations imply that SST responds in an inphase manner on the interannual timescale to ENSO fluctuations. The plot was generated using data and the online reanalysis tool provided by the NOAA Earth System Research Laboratory (http://www. esrl.noaa.gov/psd/data/correlation/). WEP, Western Equatorial Pacific; EEP, Eastern Equatorial Pacific.

above the modern lysocline [Martinez, 1994] and measurements of both weight percent $\mathrm{CaCO}_{3}$ and foraminiferal shell weights show no significant downcore trends. There is thus no evidence for significant calcite dissolution or diagenetic alteration in the record. The downcore stable isotope and trace metal records are therefore considered to accurately reflect their primary depositional values and may be used for paleoenvironmental reconstruction.

[13] The MD06-3018 core age model is based on orbital tuning of the Cibicides wuellerstorfi $\delta^{18} \mathrm{O}_{\text {benthic }}$ record to the LR04 stack [Lisiecki and Raymo, 2005], one biostratigraphic datum and the identification of four independently dated paleomagnetic polarity events [Russon et al., 2009]. The core age model yields a core base age of $1550 \mathrm{kyr}$ and a mean sedimentation rate of $20 \mathrm{~mm} / \mathrm{kyr}$ over the past $400 \mathrm{kyr}$ and $15 \mathrm{~mm} / \mathrm{kyr}$ before this [Russon et al., 2009]. The geochemical sampling strategy pursued is such that the average temporal resolution of the geochemical data presented here is $\sim 5 \mathrm{kyr}$.

\subsection{Stable Isotope Measurements}

[14] Specimens of Globigerinoides ruber (white) were picked from the $250-315 \mu \mathrm{m}$ size fraction. Different morphotypes of $G$. ruber are known to have different environmental preferences [Löwemark et al., 2005; Sadekov et al., 2008; Steinke et al., 2005] and, therefore, only the G. ruber morphotype (hereafter referred to as G. ruber) was selected. Twelve to fifteen individuals were used for each isotopic analysis. Samples were rinsed, with tests unbroken, for $10 \mathrm{~s}$ in an ultrasonic bath in methanol and then rinsed in deionized water. Samples were analyzed in the Thermo Delta+ mass spectrometer at the School of GeoSciences, University of Edinburgh. Long-term reproducibility was $2 \sigma=0.18 \%$ o for $\delta^{18} \mathrm{O}$, based on standards correlated to NBS19. Short-term reproducibility based on four downcore repeat measurements (ten measurements at each depth) was $2 \sigma=0.30 \%$.

\subsection{Mg/Ca Measurements, Mg-SST Calibration, and Calculation of $\delta^{18} \mathbf{O}_{\text {sw }}$}

[15] The MD06-3018 Mg/Ca record, as presented by Russon et al. [2010], was measured using a standard sample preparation method [Barker et al., 2003] and the intensityratio calibration method [de Villiers et al., 2002] on a Varian VISTA Pro ICP-OES (Axial) in the School of GeoSciences, University of Edinburgh. Long-term reproducibility, based on repeat measurements of carbonate standard material ECRM-521 [Greaves et al., 2005; Greaves et al., 2008] was $2 \sigma=0.0352 \mathrm{mmol} / \mathrm{mol}$ and short-term reproducibility, based on four downcore repeated (at least five measurements at each depth, including full replication of picking and cleaning stages) foraminiferal measurements, was $2 \sigma=$ $0.52 \mathrm{mmol} / \mathrm{mol}$.

[16] The exponential relationship observed between the amounts of $\mathrm{Mg}$ incorporated into foraminiferal calcite and the surrounding water temperature has been validated in many studies [Anand et al., 2003; Elderfield and Ganssen, 2000; Kisakurek et al., 2008; McConnell and Thunell, 2005; Sadekov et al., 2008]. However, the constants that define the calibration have been shown to vary between taxa, size fraction and with other factors. The MD06-3018 G. ruber $\mathrm{Mg} / \mathrm{Ca}$ record is calibrated to SST using a sediment trap based calibration for the $250-350 \mu \mathrm{m}$ size fraction without a preassumed partition coefficient [Anand et al., 2003]. This calibration function is preferred as it is based on a similar size fraction and cleaning method to the samples used here. No correction for carbonate dissolution is included within the calibration, as the core location of MD06-3018 is not significantly affected by this process. In general, the uncertainty in absolute SST values associated 


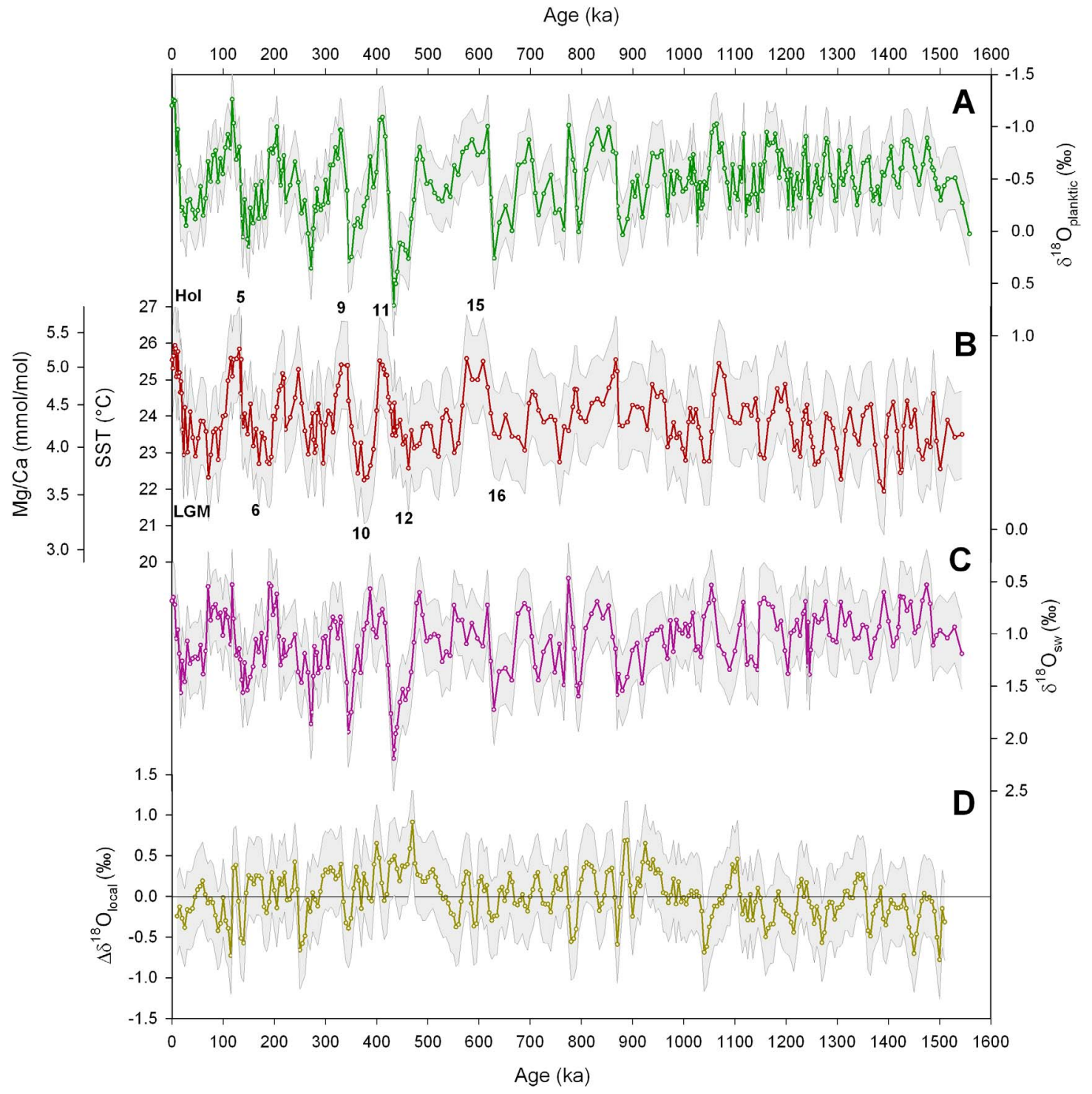

Figure 2. MD06-3018 G. ruber measurements of (a) $\delta^{18} \mathrm{O}_{\text {planktic }}$ and (b) $\mathrm{Mg} / \mathrm{Ca}$-derived SST [Russon et al., 2010] plotted against core age model. Annotations on $\mathrm{Mg} / \mathrm{Ca}$ plot show positions of selected MIS referred to in the text. (c) Calculated MD06-3018 $\delta^{18} \mathrm{O}_{\text {sw }}$ plotted against core age model. (d) Calculated $\Delta \delta^{18} \mathrm{O}_{\text {local }}$ at $5 \mathrm{kyr}$ resolution following tuning of the $\delta^{18} \mathrm{O}_{\mathrm{sw}}$ record to the Sosdian and Rosenthal [2009] $\delta^{18} \mathrm{O}_{\mathrm{sw}}$ record. Shaded areas represent $2 \sigma$ reproducibility error envelopes.

with the calibration function constants, not to mention the choice of calibration itself, is relatively large (of the order of several ${ }^{\circ} \mathrm{C}$ ) compared to that arising from sample reproducibility $\left(2 \sigma=1.0^{\circ} \mathrm{C}\right.$ in this study) or analytical precision $\left(2 \sigma=0.1^{\circ} \mathrm{C}\right.$ in this study). Consequently, reconstructed downcore variability in SST, which is the focus of the present study, is more robust than reconstructed absolute values of past SST.

[17] As $\delta^{18} \mathrm{O}_{\text {planktic }}$ depends principally on the ambient seawater temperature (taken as SST in the case of $G$. ruber) and the isotopic composition of the seawater $\left(\delta^{18} \mathrm{O}_{\mathrm{sw}}\right)$, it follows that if $\delta^{18} \mathrm{O}_{\text {planktic }}$ is measured and SST reconstructed (from $\mathrm{Mg} / \mathrm{Ca}$ in the present case) then $\delta^{18} \mathrm{O}_{\mathrm{sw}}$ may be directly calculated [Elderfield and Ganssen, 2000]. This is achieved here using the paleotemperature equation for $O$. universa (low light) which has also been shown to also apply well to G. ruber [Bemis et al., 1998]. The uncertainty in $\delta^{18} \mathrm{O}_{\mathrm{sw}}$ is calculated from the reproducibility uncertainties in $\delta^{18} \mathrm{O}_{\text {planktic }}$ and $\mathrm{Mg} / \mathrm{Ca}$-derived SST using standard error propagation formulae. The calculated core top $\delta^{18} \mathrm{O}_{\mathrm{sw}}$ value is $0.69 \pm 2 \sigma=0.34 \%$, which compares well with the gridded modern value [LeGrande and Schmidt, 2006].

[18] A proxy for past changes in the regional hydrological cycle (namely the precipitation/evaporation balance), relative to the modern, may be derived from the regional component of past $\delta^{18} \mathrm{O}_{\mathrm{sw}}$ variability, normalized to the modern. This term, $\Delta \delta^{18} \mathrm{O}_{\text {local }}$, is calculated by subtracting 


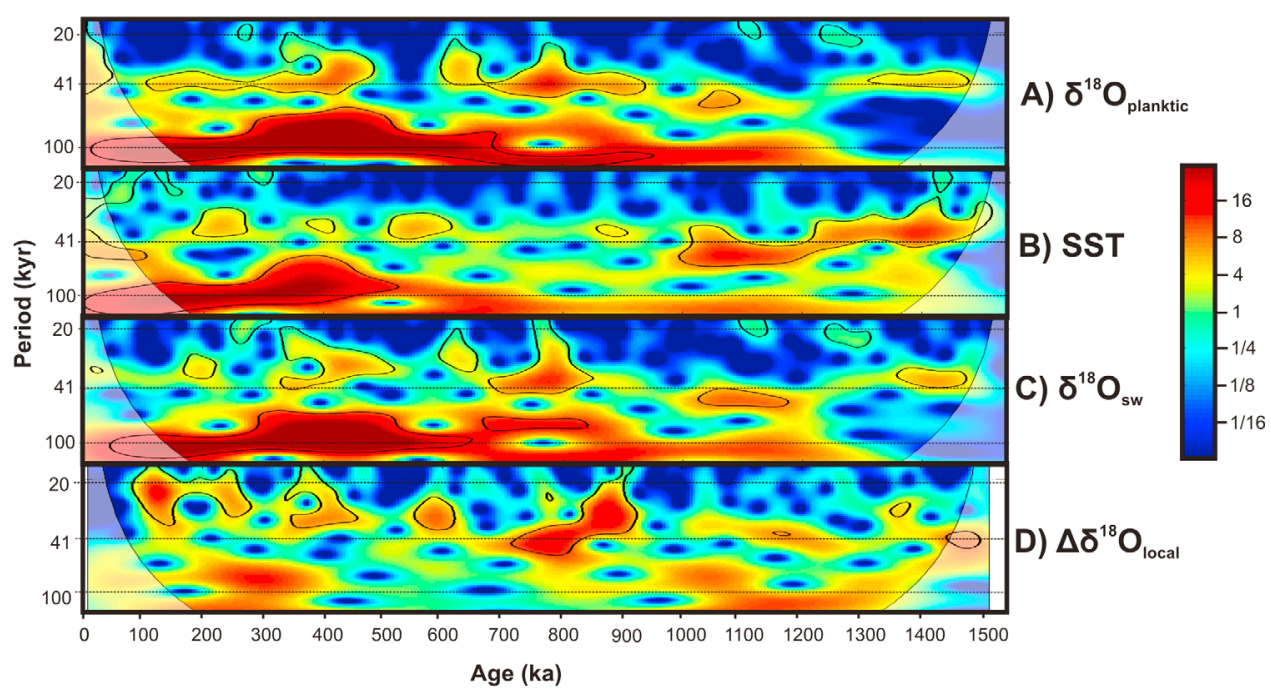

Figure 3. Local wavelet power spectra of MD06-3018 (a) G. ruber $\delta^{18} \mathrm{O}_{\text {planktic, (b) G. ruber } \mathrm{Mg} / \mathrm{Ca}-}$ derived SST, (c) calculated $\delta^{18} \mathrm{O}_{\text {sw }}$, and (d) calculated $\Delta \delta^{18} \mathrm{O}_{\text {local }}$ records. The $\delta^{18} \mathrm{O}_{\text {sw }}$ record was retuned to the Sosdian and Rosenthal [2009] age scale and all records were resampled (via linear interpolation) to $5 \mathrm{kyr}$ resolution, detrended, and normalized to unit variance prior to analysis. Wavelet decomposition was performed using the WTC-16 code [Grinsted et al., 2004]. Color bar shows spectral power in normalized units of variance. Black contour lines show $5 \%$ confidence intervals above a modeled first-order autoregressive red-noise process. Shaded areas show the cone of interference, within which edge effects become significant.

the component of global $\delta^{18} \mathrm{O}_{\mathrm{sw}}$ variability from the MD06$3018 \delta^{18} \mathrm{O}_{\mathrm{sW}}$ reconstruction. This is achieved in the present study by using an estimate of Plio-Pleistocene global $\delta^{18} \mathrm{O}_{\mathrm{sw}}$ variability derived from $\delta^{18} \mathrm{O}_{\text {benthic }}$ and reconstructed deep water temperature [Sosdian and Rosenthal, 2009]. To reduce age model artifacts in the calculation of $\Delta \delta^{18} \mathrm{O}_{\text {local }}$, the MD06-3018 $\delta^{18} \mathrm{O}_{\text {sw }}$ record was retuned (using maxima and minima points in both records) to the Sosdian and Rosenthal [2009] timescale. To allow direct comparison, both records were then resampled, via linear interpolation, to $5 \mathrm{kyr}$ resolution, meaning that the $\Delta \delta^{18} \mathrm{O}_{\text {local }}$ record is presented at that resolution. The combined error on $\Delta \delta^{18} \mathrm{O}_{\text {local }}$ is based on the assumption of the MD06-3018 $\delta^{18} \mathrm{O}_{\text {sw }}$ reproducibility error for both reconstructions. Although doubts have been raised regarding the methodology used in the Sosdian and Rosenthal [2009] reconstruction [Yu and Broecker, 2010], its application in the present study is limited to the identification of significant periodic signals in the downcore calculated residual $\Delta \delta^{18} \mathrm{O}_{\text {local }}$ record, rather than the quantification of their amplitudes.

[19] The present study does not apply a correction for the effect of past salinity variations on the coupled $\delta^{18} \mathrm{O}-\mathrm{Mg} / \mathrm{Ca}$ proxy system [Mathien-Blard and Bassinot, 2009]. The proposed correction suggests that uncorrected $\mathrm{Mg} / \mathrm{Ca}-$ derived SST reconstructions will underestimate the amplitude of glacial-interglacial SST change. However, for the LGM-Holocene transition at least, the MD06-3018 Mg/Caderived SST amplitude is consistent with existing multiproxy estimates of SST amplitude [Waelbroeck et al., 2009], meaning that there is no clear justification for the application of a correction. No correction is also applied for past variability in the $\mathrm{Mg} / \mathrm{Ca}$ composition of seawater [Medina-
Elizalde et al., 2008], as such a correction does not significantly alter the amplitudes of glacial-interglacial variability over the duration of the MD06-3018 records.

\section{Results}

[20] When plotted against the core age model the MD06$3018 \quad \delta^{18} \mathrm{O}_{\text {planktic }} \mathrm{Mg} / \mathrm{Ca}$-derived SST and calculated $\delta^{18} \mathrm{O}_{\mathrm{sw}}$ records all show a clear change in the mode of glacial-interglacial variability across the period $1000-500 \mathrm{ka}$, corresponding to that of the MPT (Figures 2a-2c). In particular, all of these records show a transition from a regime of lower amplitude, $\sim 40 \mathrm{kyr}$ period cycles prior to $\sim 1000$ ka to a regime of higher amplitude, $\sim 100 \mathrm{kyr}$ period cycles over the past $\sim 500 \mathrm{kyr}$. In contrast, the calculated $\Delta \delta^{18} \mathrm{O}_{\text {local }}$ record does not show such an evident transition (Figure 2d).

[21] Analysis of the records in age-period-spectral power space using a wavelet decomposition method [Grinsted et al., 2004] allows the evolving periodicities in the records to be studied in more detail (Figure 3). The wavelet transform method employed here includes autoregressive evaluation of spectral power significance against a modeled red-noise process. This approach does not account for the effect on spectral significance of uncertainties in the proxy values themselves, but does nonetheless allow for the more objective identification of the timing of changes in the spectral properties of a given time series. The MD06-3018 records were all resampled, via linear interpolation, to $5 \mathrm{kyr}$ spacing (the average sample spacing on the core age model), prior to the wavelet decomposition, leading to a Nyquist period of $10 \mathrm{kyr}$. This means that the range of periodicities 
associated with the orbital precession cycle (18-21 kyr) lie within, but at the limit of, what can be resolved using the present data and method.

[22] The $\delta^{18} \mathrm{O}_{\text {planktic }}$ record shows significant spectral power at $\sim 100 \mathrm{kyr}$ over the past $950 \mathrm{kyr}$ (Figure 3a). Spectral power at $\sim 40 \mathrm{kyr}$ is present, but of intermittent significance across the record. The average amplitude of $\delta^{18} \mathrm{O}_{\text {planktic }}$ variability prior to $950 \mathrm{ka}$ was $0.7 \%$ (Figure $2 \mathrm{a}$ ). After the onset of significant $\sim 100 \mathrm{kyr}$ periodicity, the glacial-interglacial amplitude increased to a maximum of $1.7 \%$ at the marine isotope stage (MIS) 12 to 11 transition. Over the last four $100 \mathrm{kyr}$ cycles the amplitude declined to $1.0 \%$ at the LGM-Holocene transition.

[23] The $\mathrm{Mg} / \mathrm{Ca}$-derived SST record shows significant spectral power at $\sim 100$ kyr over the past $550 \mathrm{kyr}$ (Figure $3 \mathrm{~b}$ ). Prior to this, spectral power in the 120-145 kyr band is present from the beginning of the record to the emergence of the significant $\sim 100 \mathrm{kyr}$ power, but is seen to have not been statistically significant. Spectral power at $\sim 40 \mathrm{kyr}$ is noticeable throughout the record but was persistently significant and of higher spectral power prior to $\sim 1000 \mathrm{ka}$. The average amplitude of glacial-interglacial SST variability over the past $550 \mathrm{kyr}$ is seen to have been $3.0^{\circ} \mathrm{C} \pm 2 \sigma=0.4^{\circ} \mathrm{C}$ (Figure 2b), whereas prior to $550 \mathrm{ka}$ it was $1.7^{\circ} \mathrm{C} \pm 2 \sigma=0.8^{\circ} \mathrm{C}$, demonstrating that the SST amplitude increased by $\sim 40 \%$ with the emergence of the $\sim 100 \mathrm{kyr}$ mode.

[24] The calculated $\delta^{18} \mathrm{O}_{\mathrm{sw}}$ record generally resembles the $\delta^{18} \mathrm{O}_{\text {planktic }}$ record more closely than the $\mathrm{Mg} / \mathrm{Ca}$-derived SST record, both in age space (Figure 2c) and in the wavelet decomposition (Figure 3c). The retuned $\delta^{18} \mathrm{O}_{\mathrm{sw}}$ record shows significant spectral power at $\sim 100 \mathrm{kyr}$ over the past 900 kyr. Spectral power at $\sim 40 \mathrm{kyr}$ is present, but of intermittent significance across the record. The average amplitude of $\delta^{18} \mathrm{O}_{\mathrm{sw}}$ variability prior to $900 \mathrm{ka}$ was $0.5 \%$. After the onset of significant $\sim 100$ kyr periodicity, the glacialinterglacial amplitude declined from $\sim 1.5 \%$ at the MIS 12/11 transition to $0.6 \%$ at the LGM-Holocene transition.

[25] The MD06-3018 $\delta^{18} \mathrm{O}_{\mathrm{sw}}$ record shows amplitudes of $\sim 100 \mathrm{kyr}$ middle/late Pleistocene and $\sim 40$ kyr early Pleistocene glacial-interglacial variability generally within the propagated $\delta^{18} \mathrm{O}_{\mathrm{sw}}$ reproducibility error of the global component of $\delta^{18} \mathrm{O}_{\mathrm{sw}}$ variability attributable to ice volume fluctuations [Sosdian and Rosenthal, 2009]. This has the consequence of removing most significant glacial-interglacial variability from the calculated $\Delta \delta^{18} \mathrm{O}_{\text {local }}$ signal and, indeed, no significant spectral power at $\sim 100 \mathrm{kyr}$ is seen across the duration of the record (Figure $3 \mathrm{~d}$ ). The $\Delta \delta^{18} \mathrm{O}_{\text {local }}$ record does, however, show patchy intervals of significant spectral power at $\sim 40 \mathrm{kyr}$ up to $\sim 700 \mathrm{kyr}$ and then in the 20 $40 \mathrm{kyr}$ range over the past $\sim 700 \mathrm{kyr}$. The amplitude of this variability lies in the $0.5-1.0 \%$ range across the duration of the record (Figure $2 \mathrm{~d}$ ) and thus exceeds the propagated error arising from the subtraction of the two $\delta^{18} \mathrm{O}_{\mathrm{sw}}$ records $( \pm 2 \sigma=$ $0.48 \%$ ). This suggests that, even given the uncertainties associated with the age model correlations and the global $\delta^{18} \mathrm{O}_{\mathrm{sw}}$ record itself, much of this variability is distinct from noise. Although exact values cannot be meaningfully given, application of the slope of the modern $\delta^{18} \mathrm{O}_{\mathrm{sw}}$-salinity relationship for the South Pacific [LeGrande and Schmidt, 2006] would imply corresponding regional salinity fluctua- tions of the order of $0.1-1.0 \mathrm{psu}$. The long-term ( $>100 \mathrm{kyr})$ mean of the $\Delta \delta^{18} \mathrm{O}_{\text {local }}$ record is seen to have remained within error of zero throughout the duration of the record.

\section{Discussion}

\subsection{Orbital Influences on Subtropical Southwest Pacific SST Variability}

[26] The MD06-3018 Mg/Ca-derived SST reconstruction shows a clear MPT from a regime of $\sim 2^{\circ} \mathrm{C}$ amplitude, $\sim 40 \mathrm{kyr}$ cycles prior to $\sim 1000$ ka to a regime of $\sim 3^{\circ} \mathrm{C}$ amplitude, $\sim 100 \mathrm{kyr}$ cycles over the past $\sim 500 \mathrm{kyr}$ (Figures $2 \mathrm{~b}$ and $3 b$ ). To investigate the relative importance of different orbital influences on this evolving pattern of reconstructed SST variability, cross-spectral analysis of the SST record with those of both obliquity angle and the precession index from the Laskar et al. [2004] orbital solution (La04) was undertaken using a wavelet transform coherence method [Grinsted et al., 2004] (Figures 4a and 4b). The SST reconstruction is seen to display significant coherence with the obliquity cycle (at the $95 \%$ confidence level against red noise, based on Monte Carlo analysis) and to be almost inphase with it across almost the entire duration of the record (Figure 4a). In contrast, the SST reconstruction only shows significant coherence with the precession index during patchy intervals throughout the record and a much more variable phase relationship (Figure $4 b$ ). It appears, therefore, that the obliquity cycle has exerted the dominant orbital influence on subtropical southwest Pacific SST variability, both before, during and after the MPT.

[27] The origins of the $\sim 100 \mathrm{kyr}$ middle/late Pleistocene mode of glacial-interglacial variability continues to be debated. While $\sim 100 \mathrm{kyr}$ spectral power is the dominant characteristic of the past $\sim 500 \mathrm{kyr}$ in the subtropical southwest Pacific SST reconstruction (Figure 3b), significant coherence with the obliquity cycle, but not the precession index, is seen to be maintained across most of this interval (Figure 4a). Closer examination of the structure of the middle/late Pleistocene SST cycles demonstrate that these are in fact more symmetric than the classic "sawtooth" $100 \mathrm{kyr}$ pattern seen in the LR04 $\delta^{18} \mathrm{O}_{\text {benthic }}$ stack and taken here as a crude first-order proxy for both global ice volume fluctuations and the northern high-latitude climate response (Figure 5a). Instead, periods of relatively rapid cooling in the subtropical SST reconstruction follow the interglacial SST maxima and are followed by longer periods of relatively stable low SST. These differences are not an artifact of age model comparisons as the MD06-3018 $\delta^{18} \mathrm{O}_{\text {benthic }}$ record, which was tuned to LR04, but is derived from the same depth space as the MD06-3018 SST record, also shows the same differences from the SST record (Figure 5a). The "interglacial" parts of each 100 kyr subtropical SST cycle, defined here as when SST exceeds $24^{\circ} \mathrm{C}$ (the long-term mean value of the reconstruction over the past $800 \mathrm{kyr}$ ), are seen to be coincident with individual obliquity cycles, such that maximum SST corresponds to maximum obliquity (Figure 5a). The apparent exceptions at 200-250 ka (around MIS 7) and 560-630 ka (around MIS 15) are related to dual SST maxima separated by weak SST minima, but these are still seen to remain in phase with 


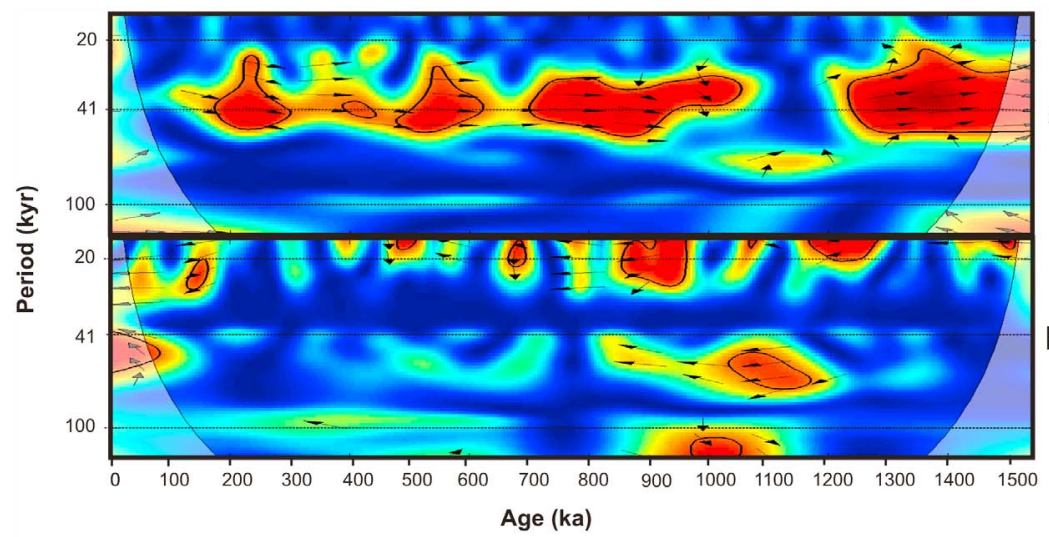

\section{A) Obliquity \\ SST}

B) Precession
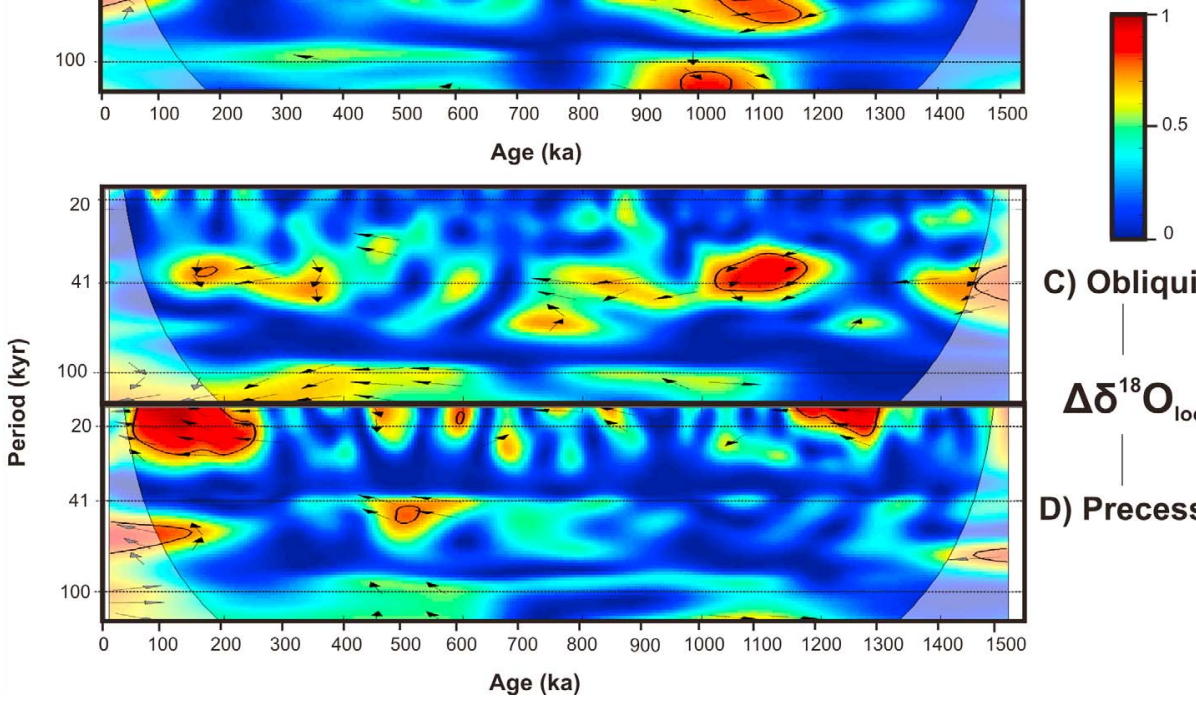

C) Obliquity

$\Delta \delta^{18} \mathrm{O}_{\text {local }}$

D) Precession

Figure 4. Wavelet transform coherence analysis of the MD06-3018 G. ruber (a and b) $\mathrm{Mg} / \mathrm{Ca}$-derived SST and (c and d) calculated $\Delta \delta^{18} \mathrm{O}_{\text {local }}$ records with orbital obliquity and precession index records from the La04 orbital solution [Laskar et al., 2004]. Analysis was performed using the WTC-16 code [Grinsted et al., 2004]. Color bar shows squared coherence $\left(\mathrm{C}_{\mathrm{xy}}^{2}\right)$ level. Black contour lines show $5 \%$ confidence intervals relative to red noise, determined using a Monte Carlo method. For areas of age-period space with significant coherence, the phase relationship between the two variables is shown by black arrows. Right (left) pointing horizontal arrows denote an in-phase (antiphase) relationship. All records were resampled (via linear interpolation) to $5 \mathrm{kyr}$ resolution, detrended, and normalized to unit variance prior to analysis. Shaded areas show the cone of interference, within which edge effects become significant.

the obliquity variations. Therefore, the $100 \mathrm{kyr}$ glacialinterglacial mode in subtropical southwest Pacific SST seems to be closely paced by the obliquity cycle, consistent with the persistent coherence relationship seen in Figure 4a.

[28] The combined effect of the various orbital cycles on mean annual insolation at $23^{\circ} \mathrm{S}$ is dominated by the effect of obliquity cycle. However, as has been previously documented for the equatorial Pacific [Liu and Herbert, 2004], this variability in local insolation forcing is almost exactly out of phase with the reconstructed subtropical southwest Pacific SST variability, even during the early Pleistocene where a dominant $\sim 40$ kyr period is seen in both records. This means that the apparently obliquity paced variations in SST almost certainly cannot be a direct consequence of the effect of the orbital variations on local, low-latitude insolation. However, because changes in mean annual insolation arising from obliquity fluctuations are out of phase between the low- and high-latitudes (but in phase between the two hemispheres), it also follows that the phase of the reconstructed SST response would be consistent with the effect of the obliquity cycle on either the northern or southern high latitudes.

[29] The observation that equatorial Pacific SST reconstructions are coherent with, but lead records of $\delta^{18} \mathrm{O}_{\text {benthic }}$ across the Pleistocene glacial-interglacial cycles suggests that the origin of the high-latitude sensitivity in wider low-latitude SST is unlikely to be in the northern hemisphere [Liu and Herbert, 2004; Medina-Elizalde and Lea, 2005]. However, this lead/lag relationship has been shown to also be potentially explicable by other factors [Ashkenazy and Tziperman, 2006]. The structure of the middle/late Pleistocene $\sim 100$ kyr SST cycles seen in the MD06-3018 reconstruction now provides an alternative approach to the problem, at least in the case of the subtropical southwest Pacific.

[30] The pattern of long periods of low SST separated by $\sim 40$ kyr intervals of near symmetric warming and then cooling is similar to that seen in $\delta D$ records from Antarctic ice cores [Jouzel et al., 2007] (Figure 5c), taken here as a first-order proxy for high-latitude southern hemisphere climate. The interval of greatest discrepancy between the two 


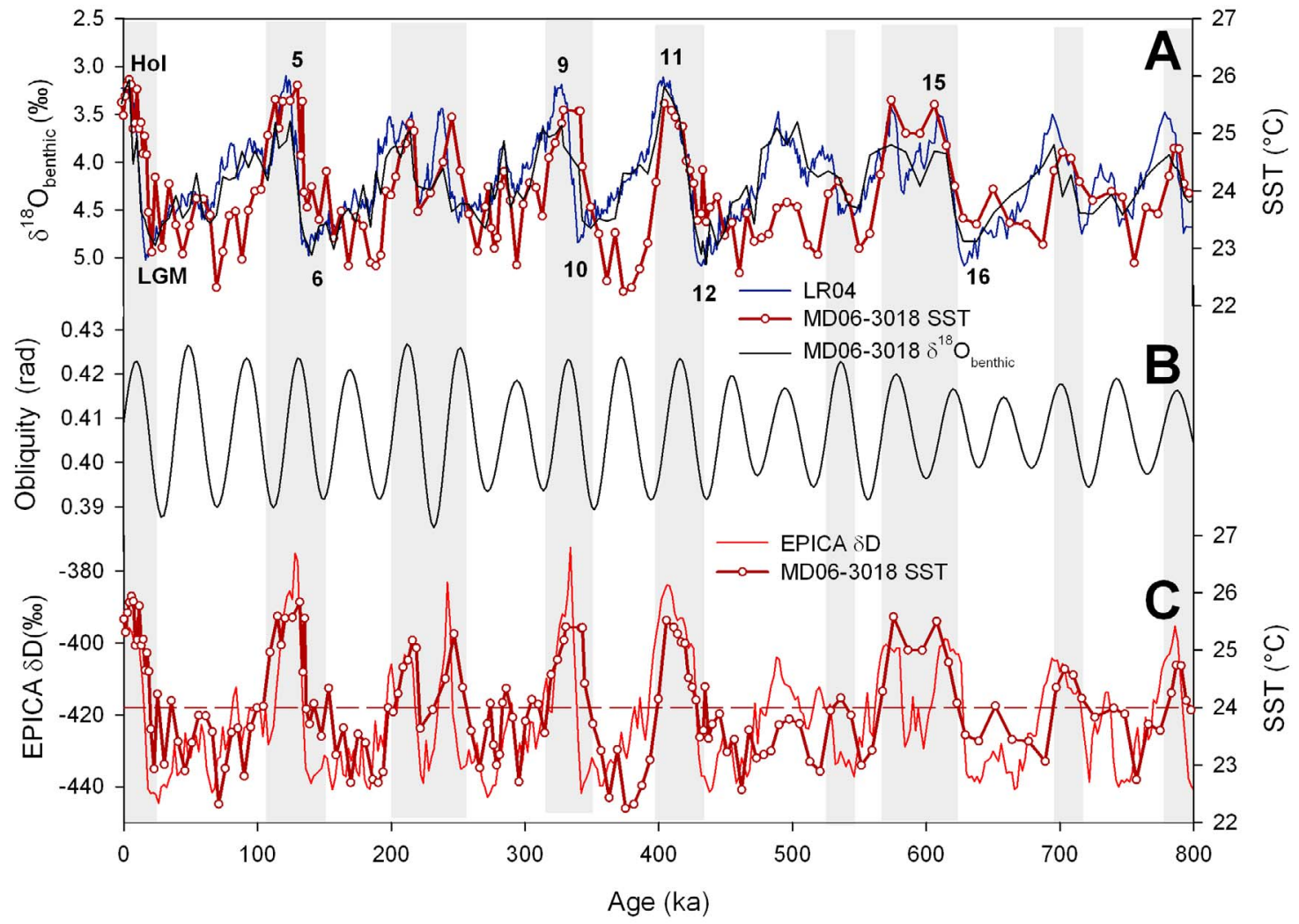

Figure 5. Plots over the past $800 \mathrm{kyr}$ of (a) MD06-3018 G. ruber $\mathrm{Mg} / \mathrm{Ca}$-derived SST, MD06-3018 Cibicides wuellerstorfi $\delta^{18} \mathrm{O}_{\text {benthic, }}$, and the LR04 $\delta^{18} \mathrm{O}_{\text {benthic }}$ stack [Lisiecki and Raymo, 2005]. Numbers refer to same selected MIS shown in Figure 2. (b) Orbital obliquity from the La03 solution [Laskar et al., 2004]. (c) MD06-3018 G. ruber $\mathrm{Mg} / \mathrm{Ca}$-derived SST versus European Project for Ice Coring in Antarctica (EPICA) composite $\delta D$ record, resampled (via linear interpolation) to $2 \mathrm{kyr}$ resolution [Jouzel et al., 2007]. Dashed line shows $24^{\circ} \mathrm{C}$ reference level (the long-term average of the SST reconstruction over the past $800 \mathrm{kyr}$ ), and gray shading shows periods when SST exceeds this.

records at 550-600 ka may be partly accounted for uncertainties in the MD06-3018 age model over that interval. The SST to $\delta D$ similarity is in contrast to the differences observed between the SST reconstruction and the LR04 $\delta^{18} \mathrm{O}_{\text {benthic }}$ stack (Figure 5a) and supports the supposition that, during the middle/late Pleistocene at least, the origin of the strong obliquity signal within the subtropical southwest Pacific SST reconstruction was located in the southern, rather than northern, high latitudes. The question of what processes may have acted to communicate this signal into the low-latitude climate response is considered in section 4.4.

\subsection{Orbital Influences on Subtropical Southwest Pacific Hydrological Cycle Variability}

[31] The MD06-3018 $\Delta \delta^{18} \mathrm{O}_{\text {local }}$ reconstruction of regional hydrological cycle variability is subject to larger amplitude and phase uncertainties than the SST reconstruction as it depends upon both the uncertainties in the SST record itself and also the additional uncertainties arising from the correlation of two separate core age models. Even bearing this in mind, however, it is immediately evident that the spectral properties of the $\Delta \delta^{18} \mathrm{O}_{\text {local }}$ and SST records show significant differences over the past $1500 \mathrm{kyr}$ (Figures $3 \mathrm{~b}$ and $3 \mathrm{~d}$ ). Determining the orbital affinities of the significant $20-40 \mathrm{kyr}$ periodicities present in the $\Delta \delta^{18} \mathrm{O}_{\text {local }}$ reconstruction is not, however, possible from Figure $3 \mathrm{~d}$ alone. The wavelet transform coherence method, as described in section 4.1, provides a method for evaluating these dominant orbital influences on the $\Delta \delta^{18} \mathrm{O}_{\text {local }}$ record and hence, those acting on the regional hydrological cycle.

[32] The $\Delta \delta^{18} \mathrm{O}_{\text {local }}$ reconstruction shows generally lower coherence values with obliquity than was seen for SST and these values also generally decline over time such that no significant coherence is present after $\sim 1000 \mathrm{ka}$ (Figure $4 \mathrm{c}$ ). During the period prior to this, when significant coherence is present, the phase relationship between $\Delta \delta^{18} \mathrm{O}_{\text {local }}$ and obliquity is seen to be in near antiphase (the opposite of what was observed for SST). This implies that tilt maxima coincided with minima in $\Delta \delta^{18} \mathrm{O}_{\text {local }}$. Like SST, $\Delta \delta^{18} \mathrm{O}_{\text {local }}$ shows patchy coherence with the La04 precession index across the duration of the record, but in the case of $\Delta \delta^{18} \mathrm{O}_{\text {local }}$ this is seen to become both persistent and highly 
significant over the past $\sim 300 \mathrm{kyr}$ (Figure $4 \mathrm{~d}$ ). Over this interval the $\Delta \delta^{18} \mathrm{O}_{\text {local }}$ record and the precession index are also seen to be in near antiphase, again meaning that maxima in the $\mathrm{La} 04$ precession index coincided with minima in $\Delta \delta^{18} \mathrm{O}_{\text {local }}$.

\subsection{Constraints on Super-ENSO Over the MPT}

[33] Prior to $\sim 1000 \mathrm{ka}$, the MD06-3018 reconstructions of subtropical southwest Pacific SST and hydrological cycle variability both show significant coherence with the obliquity cycle (Figures $4 \mathrm{~b}$ and $4 \mathrm{~d}$ ), which could potentially be indicative of the influence of an obliquity-paced superENSO mode on the climate of the southern Coral Sea during the $40 \mathrm{kyr}$ world. The relative phase of the two reconstructions at the obliquity period is consistent with such a model, with SST maxima (minima) coinciding with $\Delta \delta^{18} \mathrm{O}_{\text {local }}$ minima (maxima), which is consistent with warm, wet La Niña-like (cool, dry El Niño-like) conditions. However, the specific hypothesis of Philander and Fedorov [2003] that the amplification of the obliquity cycle by the low-latitude ocean-climate system should favor an El Niño (La Niña) state when tilt is large (small) is in the opposite sense to what is observed in the MD06-3018 reconstructions. This does not preclude the existence of such a phenomenon, but does mean that it cannot have exerted the dominant control on either SST or hydrological cycle variability in the subtropical southwest Pacific.

[34] The absence of a persistently significant coherence relationship between the hydrological cycle reconstruction and obliquity after $\sim 1000$ ka suggests that any obliquity paced super-ENSO mechanism weakened over the MPT, with the dominant forcing mechanisms of SST and hydrological cycle variability becoming largely decoupled over the middle/late Pleistocene. In particular, whereas SST continues to exhibit significant coherence with obliquity across that time, the hydrological cycle reconstruction shows little coherence with either obliquity or precession until $\sim 300 \mathrm{ka}$. The appearance of significant and persistent coherence with the precession index at that time must necessarily be interpreted with caution, given the uncertainties associated with the derivation of the $\Delta \delta^{18} \mathrm{O}_{\text {local }}$ record and its temporal resolution. If, however, accepted at face value then the relationship may be indicative of a precession paced super-ENSO mode becoming more significant over the past $\sim 300$ kyr.

[35] The strength of the ENSO system in a strict sense on the multiannual timescale is thought to be related to the effect of precession forcing on seasonal insolation budgets within the low-latitude Pacific [Clement et al., 1999]. Furthermore, the same ENSO models also predict associated changes in the mean state of the low-latitude Pacific on the timescale of the precession cycle, with La Niña-like conditions being associated with high values of the La04 precession index. This scenario is consistent with the observed pattern of $\Delta \delta^{18} \mathrm{O}_{\text {local }}$ variability over the past $\sim 300 \mathrm{kyr}$, with high precession index values nearly coincident with negative $\Delta \delta^{18} \mathrm{O}_{\text {local }}$ values (regionally wetter conditions, as associated with the La Niña state in the regional ENSO cycle in a strict sense). In the modern climate regime, New Caledonia is more highly sensitive to ENSO fluctuations in precipitation than SST, mainly as a consequence of shifts in the position and intensity of the South Pacific Convergence Zone [Gouriou and Delcroix, 2002], with the El Niño (La Niña) mode characterized by dry (wet) conditions with interannual precipitation anomalies, relative to mean annual values, of as much as $50 \%$ observed [Nicet and Delcroix, 2000]. Thus, the absence of a corresponding pattern of precession coherence in the SST reconstruction (Figure $4 \mathrm{~b}$ ) may be attributable to the relative weakness of the SST variations (in comparison to precipitation) associated with the ENSO cycle in a strict sense at the site.

[36] The interpretation of the precession cycle relationships, in relation to those at the obliquity, is necessarily very tentative at the present, but does at least suggest that the low-latitude coupled ocean-atmosphere system may potentially have contributed to a proposed increase in the sensitivity of the global climate system precession forcing within the $100 \mathrm{kyr}$ world [Imbrie et al., 1993; Raymo, 1997]. The future study of other suborbitally resolved reconstructions of low-latitude Pacific climate variability will allow the direct testing of whether the climatic pattern observed here is part of a wider, post-MPT, precession-paced, super-ENSO response.

\subsection{Forcing Mechanisms for Low-Latitude Pacific SST Over the MPT}

[37] It has been proposed that radiative forcing arising from greenhouse gas variability dominates the low-latitude glacial-interglacial SST response, at least in the western Pacific, across the MPT [Medina-Elizalde and Lea, 2005]. Both model calculation of radiative forcing across the low latitudes for the last glacial cycle [Broccoli, 2000] and the observation that low-latitude SST variability is close to being in-phase with atmospheric $\mathrm{pCO}_{2}$ variability over the past $\sim 800$ kyr [Jouzel et al., 2007; Lea, 2004] support this interpretation. However, the MD06-3018 reconstructions of subtropical southwest Pacific SST and hydrological cycle variability also provide evidence that obliquity paced superENSO fluctuations may also have significantly influenced low-latitude western Pacific climate prior to $\sim 1000 \mathrm{ka}$.

[38] In order to better constrain the relative influences of these two mechanisms on both subtropical southwest Pacific SST in particular and SST in the wider low-latitude system in general, the MD06-3018 SST reconstruction is now compared to others from the WEP (MD97-2140) [de Garidel-Thoron et al., 2005] and the EEP (ODP site 846) [Lawrence et al., 2006]. SST anomalies associated with the ENSO cycle in a strict sense are of the same sign (but different magnitude and phase) in the WEP and the southern Coral Sea, whereas the EEP is a region of extensive upperocean ventilation and hence ENSO SST anomalies here are anticorrelated to those in the western low-latitude Pacific (Figure 1). Unlike the $\mathrm{Mg} / \mathrm{Ca}$-derived western Pacific SST reconstructions, the ODP 846 reconstruction is based on alkenone saturation indices. While the two proxy systems involve different assumptions, they have been shown to be in agreement regarding first-order trends in EEP SST over the past $5000 \mathrm{kyr}$ [Dekens et al., 2008]. The MD97-2140 and ODP 846 reconstruction are presented on the published core age models (Figure 6a). In order to analyze the 


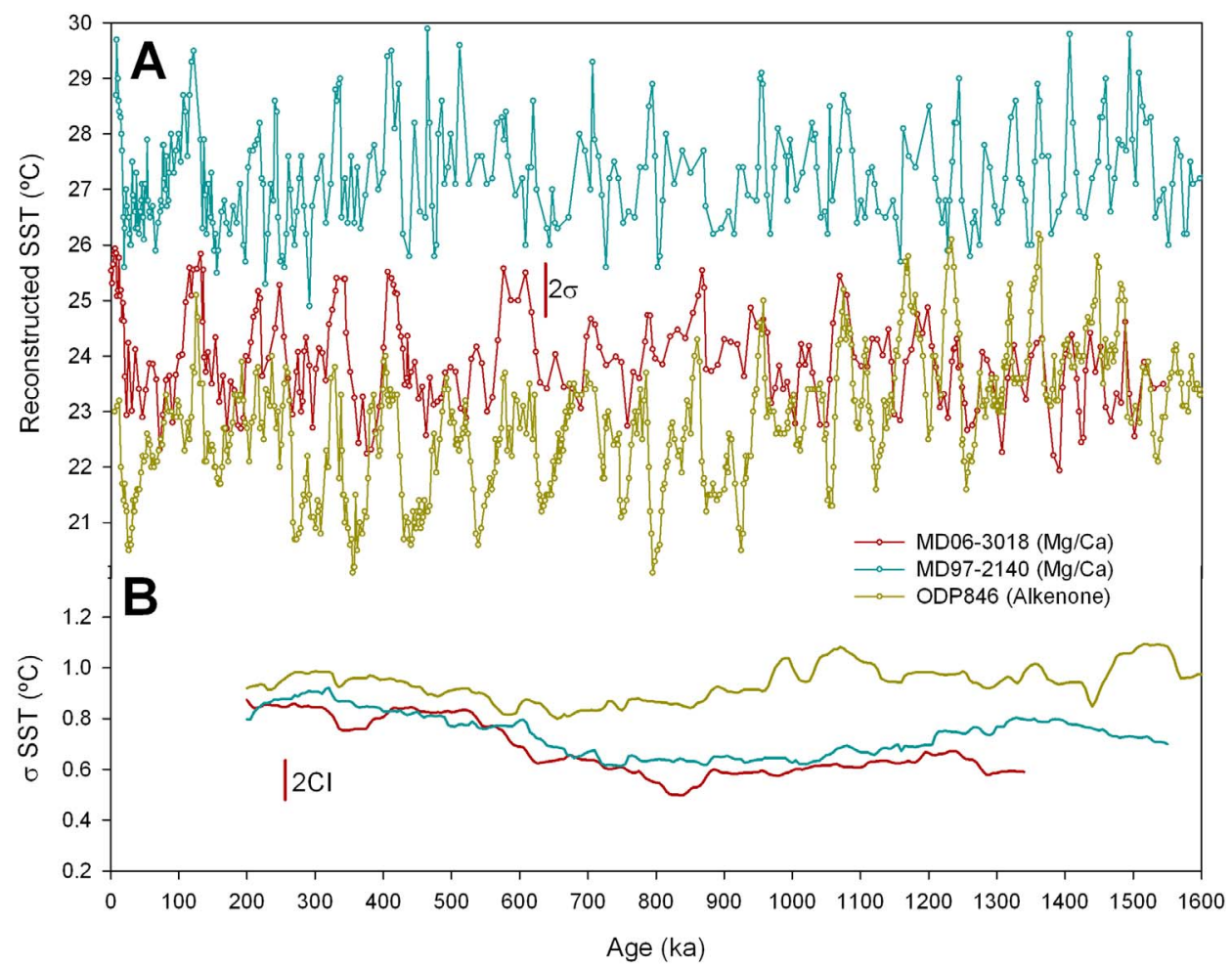

Figure 6. (a) SST reconstructions from MD06-3018 in the subtropical southwest Pacific [Russon et al., 2010], MD97-2140 in the WEP [de Garidel-Thoron et al., 2005], and ODP 846 in the EEP [Lawrence et al., 2006]. The MD06-3018 and MD97-2140 reconstructions are based on $\mathrm{Mg} / \mathrm{Ca}$, and the ODP 846 reconstruction is based on alkenone saturation index paleothermometry methods. All records are presented on published age models. Vertical bar shows MD06-3018 reproducibility uncertainty. (b) The $400 \mathrm{kyr}$ running boxcar $\sigma_{\mathrm{SST}}$ records after linear detrending. Vertical bar shows $95 \%$ confidence interval for the $\sigma_{\mathrm{SST}}$ values.

long-term (i.e., super glacial-interglacial) trends in glacialinterglacial SST variance, all records were resampled (via linear interpolation) at $5 \mathrm{kyr}$ resolution and linearly detrended prior to the calculation of a $400 \mathrm{kyr}$ moving box car standard deviation SST value $\left(\sigma_{\mathrm{SST}}\right.$, Figure $\left.6 \mathrm{~b}\right)$.

[39] The two western Pacific SST reconstructions (MD063018 and MD97-2140) are seen to be within the 95\% confidence interval on $\sigma_{\mathrm{SST}}$ of $\pm 0.15^{\circ} \mathrm{C}$ of one another throughout the past 1500 kyr (Figure 6b). There has, therefore, been no significant difference in glacial-interglacial SST variance between $2^{\circ} \mathrm{N}$ and $23^{\circ} \mathrm{S}$ in the western Pacific over this period. Furthermore, the first-order spectral properties of the two records are very similar (Figures $7 \mathrm{a}$ and $7 \mathrm{~b}$ ), suggesting that the timing of the MPT was also similar at both latitudes. These observations are most consistent with a dominant greenhouse gas (i.e., spatially uniform) forcing of the reconstructed SST variability. A contribution from super-ENSO related circulation changes cannot be ruled out, but would be required to have been both uniform in SST amplitude between the two sites, regardless of the overall strength of any orbitally paced super-ENSO modes.

[40] An additional line of evidence in support of a greenhouse gas-dominated SST response is that the timing $(\sim 500 \mathrm{ka})$ and increase in glacial-interglacial amplitude of $\sim 30 \%$ associated with the emergence of the $\sim 100 \mathrm{kyr}$ SST cycles in the MD06-3018 record are both consistent with the shift in glacial-interglacial $\mathrm{pCO}_{2}$ variability between the interval 500-800 ka and the past five cycles seen in ice core records [Lüthi et al., 2008]. If it is assumed that the early Pleistocene glacial-interglacial $\mathrm{pCO}_{2}$ cycles were at a $\sim 40 \mathrm{kyr}$ period and of similar amplitude to those of the 500 $800 \mathrm{ka}$ interval, as is supported by geochemical proxy reconstructions [Honisch et al., 2009], then this would also be consistent with the dominant influence of greenhouse gas forcing on subtropical southwest Pacific SST having persisted across at least the past $1500 \mathrm{kyr}$. The data presented here is most consistent with the contention that greenhouse gas forcing has dominated western low-latitude Pacific glacial-interglacial SST variability across the MPT and hence that the carbon cycle acts as the main communicating mechanism for the high-latitude obliquity sensitivity described in section 4.1. While the influence of super-ENSO modes on the southern Coral Sea may be detectable during the early Pleistocene, they seem unlikely to have contributed significantly to the glacial-interglacial SST amplitude.

[41] Over the past $600 \mathrm{kyr}$, the EEP $\sigma_{\mathrm{SST}}$ record is seen to have been slightly higher in value, but within the $95 \%$ 


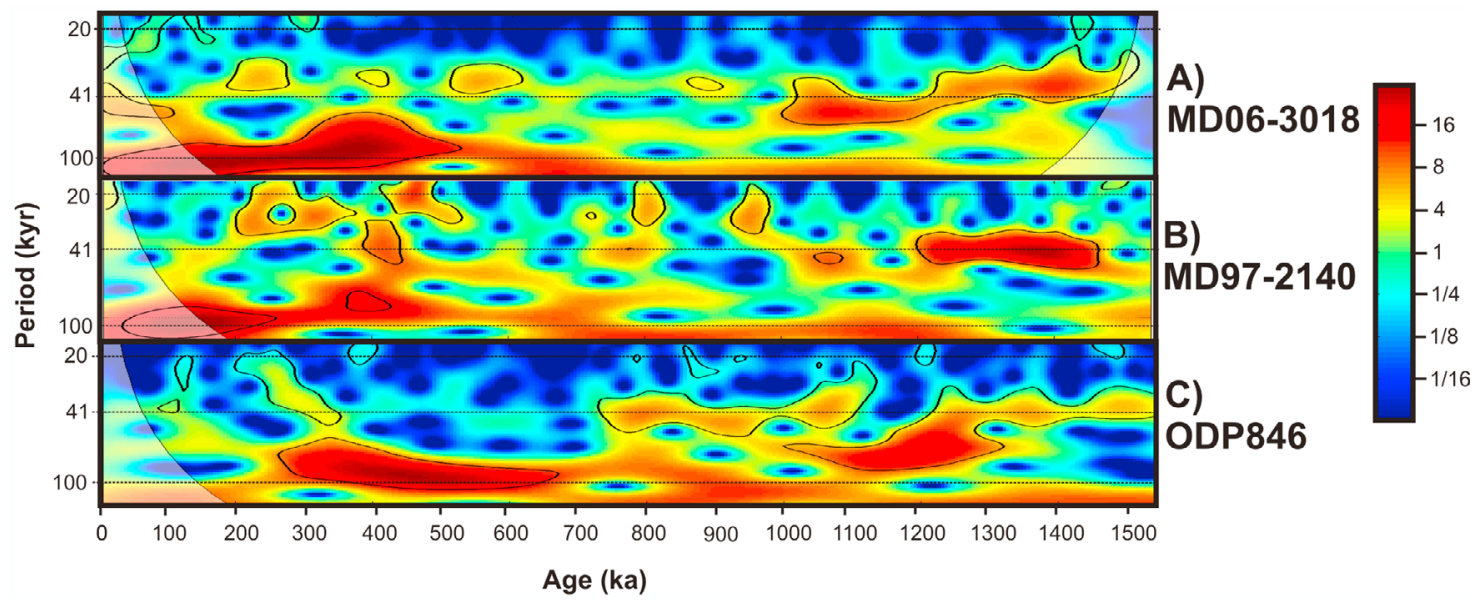

Figure 7. Local wavelet power spectra of the SST reconstructions from (a) MD06-3018, (b) MD972140, and (c) ODP 846. All records were resampled (via linear interpolation) to $5 \mathrm{kyr}$ resolution, detrended, and normalized to unit variance prior to analysis. Wavelet decomposition was performed using the WTC-16 code [Grinsted et al., 2004]. Color bar shows spectral power in normalized units of variance. Black contour lines show 5\% confidence intervals above a modeled first-order autoregressive red-noise process. Shaded areas show the cone of interference, within which edge effects become significant.

confidence interval, of those for the two western Pacific records (Figure 6b). However, in contrast to the western Pacific records, no significant increase in EEP $\sigma_{\mathrm{SST}}$ is seen over the MPT interval. The resultant difference in $\sigma_{\mathrm{SST}}$ during the early Pleistocene between the eastern and western low-latitude Pacific reconstructions exceeds the 95\% confidence interval and is not a consequence of record detrending, as the same exercise performed on the original untrended records leads to an even greater calculated difference.

[42] The observed divergence of EEP and western lowlatitude Pacific SST variance at $800-600 \mathrm{ka}$ is seen to have coincided with the decline in significant $\sim 40 \mathrm{kyr}$ spectral power $(\sim 700 \mathrm{ka})$ seen in the ODP 846 record (Figure 7c). This, therefore, supports a significantly enhanced relative contribution from upper-ocean ventilation changes to EEP glacial-interglacial SST variability during the $\sim 40$ kyr world [Philander and Fedorov, 2003; Liu and Herbert, 2004]. Thus, while greenhouse gas forcing has apparently dominated glacial-interglacial SST variability in the low-latitude western Pacific across the entire Pleistocene, the combined effect of the changes occurring during the MPT was to also increase its relative importance in areas of upwelling, such that by the end of the transition and the advent of the 100 kyr world, glacial-interglacial SST amplitudes do not significantly differ zonally across the low-latitude Pacific.

\section{Conclusions}

[43] Reconstructions of subtropical southwest Pacific SST and hydrological cycle variability across the MPT were produced from coupled downcore planktic foraminiferal $\delta^{18} \mathrm{O}-\mathrm{Mg} / \mathrm{Ca}$ measurements taken from core MD06-3018 in the southern Coral Sea. The SST reconstruction shows a strong relationship to the orbital obliquity cycle across the past 1500 kyr which must arise from a high-latitude, rather than local, sensitivity to the orbital variations. The close correspondence within the $\sim 100 \mathrm{kyr}$ world of the structure of reconstructed subtropical southwest Pacific SST variability with proxy records of Antarctic climate suggests that the origin of this sensitivity was located in the southern rather than northern high latitudes. In contrast to the SST response, reconstructed hydrological cycle variability in the subtropical southwest Pacific shows no significant change coherence with the obliquity cycle after $\sim 1000 \mathrm{ka}$, but did become more significantly coherent with the precession cycle over the past $\sim 300 \mathrm{kyr}$.

[44] The decoupling of the reconstructed SST and hydrological cycle responses indicates that obliquity paced super-ENSO fluctuations in the wider low-latitude oceanatmosphere system could only have significantly affected the climate of the southern Coral Sea prior to $\sim 1000 \mathrm{ka}$. Comparison of the MD06-3018 SST reconstruction with others from the equatorial Pacific supports the view that greenhouse gas forcing has dominated glacial-interglacial SST variability in the low-latitude western Pacific across the entire Pleistocene, including the interval when super-ENSO variations are detectable.

[45] More fundamentally, the present study has clearly demonstrated that reconstructions of different aspects of the low-latitude climate system show differing responses to orbital forcing across the MPT. This reflects the complexity of the low-latitude system on these timescales and highlights the importance of wide spatial coverage of multiproxy reconstructions in understanding the evolving modes of climate response to orbital forcing.

[46] Acknowledgments. Walter Geibert is thanked for help with the ICP-OES. Colin Chilcott is thanked for help with the mass spectrometer. The crew, scientists, and Yvon Balut from the R/V Marion Dufresne; Yves 
Lafoy (Dimenc NC); A. M. Sémah, and D. Wirrmann (IRD) are thanked for obtaining and logging the core at sea. Our thanks are expressed to the French Zonéco program, CNFE, IPEV, and IRD for contributing to the grants to obtain the core. The manuscript was improved substantially as a result of reviews from Erin McClymont and one anonymous reviewer. This work was funded through NERC PhD studentship 14325 to T. Russon.

\section{References}

Alory, G., A. Vega, A. Ganachaud, and M. Despinoy (2006), Influence of upwelling, subsurface stratification, and heat fluxes on coastal sea surface temperature off southwestern New Caledonia, J. Geophys. Res., 111, C07023, doi:10.1029/2005JC003401.

Anand, P., H. Elderfield, and M. H. Conte (2003), Calibration of $\mathrm{Mg} / \mathrm{Ca}$ thermometry in planktonic foraminifera from a sediment trap time series, Paleoceanography, 18(2), 1050, doi:10.1029/2002PA000846.

Ashkenazy, Y., and E. Tziperman (2004), Are the 41 kyr glacial oscillations a linear response to Milankovitch forcing?, Quat. Sci. Rev., 23, 1879-1890, doi:10.1016/j.quascirev. 2004.04.008.

Ashkenazy, Y., and E. Tziperman (2006), Scenarios regarding the lead of equatorial sea surface temperature over global ice volume, Paleoceanography, 21, PA2006, doi:10.1029/ 2005PA001232.

Barker, S., M. Greaves, and H. Elderfield (2003), A study of cleaning procedures used for foraminiferal $\mathrm{Mg} / \mathrm{Ca}$ paleothermometry, Geochem. Geophys. Geosyst., 4(9), 8407, doi:10.1029/ 2003GC000559.

Beaufort, L., T. de Garidel-Thoron, A. C. Mix, and N. G. Pisias (2001), ENSO-like forcing on oceanic primary production during the Late Pleistocene, Science, 293(5539), 2440-2444, doi:10.1126/science.293.5539.2440.

Bemis, B. E., H. J. Spero, J. Bijma, and D. W. Lea (1998), Reevaluation of the oxygen isotopic composition of planktonic foraminifera: Experimental results and revised paleotemperature equations, Paleoceanography, 13, 150-160, doi:10.1029/98PA00070.

Bintanja, R., and R. S. W. van de Wal (2008), North American ice-sheet dynamics and the onset of 100,000-year glacial cycles, Nature, 454, 869-872, doi:10.1038/nature07158.

Broccoli, A. J. (2000), Tropical cooling at the last glacial maximum: An atmosphere-mixed layer ocean model simulation, J. Clim., 13(5), 951-976, doi:10.1175/1520-0442(2000) 013<0951:TCATLG $>2.0$. CO;2.

Clark, P. U., and D. Pollard (1998), Origin of the middle Pleistocene transition by ice sheet erosion of regolith, Paleoceanography, 13, 1-9, doi:10.1029/97PA02660.

Clement, A. C., R. Seager, and M. A. Cane (1999), Orbital controls on the El Nino/Southern Oscillation and the tropical climate, Paleoceanography, 14, 441-456, doi:10.1029/ 1999PA900013.

Crundwell, M., G. Scott, T. Naish, and L. Carter (2008), Glacial-interglacial ocean climate variability from planktonic foraminifera during the mid-Pleistocene transition in the temperate Southwest Pacific, ODP Site 1123, Palaeogeogr. Palaeoclimatol. Palaeoecol., 260(1-2), 202-229, doi:10.1016/j.palaeo.2007.08.023

de Garidel-Thoron, T., Y. Rosenthal, F. Bassinot, and L. Beaufort (2005), Stable sea surface temperatures in the western Pacific warm pool over the past 1.75 million years, Nature, 433, 294-298, doi:10.1038/nature03189.

Dekens, P. S., A. C. Ravelo, M. D. McCarthy, and C. A. Edwards (2008), A 5 million year comparison of $\mathrm{Mg} / \mathrm{Ca}$ and alkenone paleotherm- ometers, Geochem. Geophys. Geosyst., 9, Q10001, doi:10.1029/2007GC001931.

Delcroix, T., and O. Lenormand (1997), ENSO signals in the vicinity of New Caledonia, South Western Pacific, Oceanol. Acta, 20(3), 481-491

de Villiers, S., M. Greaves, and H. Elderfield (2002), An intensity ratio calibration method for the accurate determination of $\mathrm{Mg} / \mathrm{Ca}$ and $\mathrm{Sr} / \mathrm{Ca}$ of marine carbonates by ICP-AES, Geochem. Geophys. Geosyst., 3(1), 1001 , doi:10.1029/2001GC000169.

Elderfield, H., and G. Ganssen (2000), Past temperature and $\delta^{18} \mathrm{O}$ of surface ocean waters inferred from foraminiferal $\mathrm{Mg} / \mathrm{Ca}$ ratios, Nature, 405, 442-445, doi:10.1038/35013033.

Elkibbi, M., and J. A. Rial (2001), An outsider's review of the astronomical theory of the climate: Is the eccentricity-driven insolation the main driver of the ice ages?, Earth Sci. Rev., 56, 161-177, doi:10.1016/S0012-8252(01) 00061-7.

Gouriou, Y., and T. Delcroix (2002), Seasonal and ENSO variations of sea surface salinity and temperature in the South Pacific Convergence Zone during 1976-2000, J. Geophys Res., 107(C12), 3185, doi:10.1029/ 2001JC000830.

Greaves, M., S. Barker, C. Daunt, and H. Elderfield (2005), Accuracy, standardization, and interlaboratory calibration standards for foraminiferal $\mathrm{Mg} / \mathrm{Ca}$ thermometry, Geochem. Geophys. Geosyst., 6, Q02D13, doi:10.1029/2004GC000790.

Greaves, M., et al. (2008), Interlaboratory comparison study of calibration standards for foraminiferal $\mathrm{Mg} / \mathrm{Ca}$ thermometry, Geochem. Geophys. Geosyst., 9, Q08010, doi:10.1029/ 2008GC001974.

Grinsted, A., J. C. Moore, and S. Jevrejeva (2004), Application of the cross wavelet transform and wavelet coherence to geophysical time series, Nonlinear Processes Geophys. 11(5-6), 561-566, doi:10.5194/npg-11-5612004

Hays, J. D., J. Imbrie, and N. J. Shackleton (1976), Variations in Earth's orbit: Pacemaker of the Ice Ages, Science, 194(4270), 11211132, doi:10.1126/science.194.4270.1121.

Head, M. J., and P. L. Gibbard (2005), Early middle Pleistocene transitions: An overiew and recommendation for the defining boundary, in Early Middle Pleistocene transitions: The Land-Ocean Evidence, edited by M. J. Head and P. L. Gibbard, pp. 1-18, Geol. Soc., London.

Hénin, C., and G. R. Cresswell (2005), Upwelling along the western barrier reef of New Caledonia, Mar. Freshwater Res., 56(7), 10051010, doi:10.1071/MF04266.

Honisch, B., N. G. Hemming, D. Archer, M. Siddall, and J. F. McManus (2009), Atmospheric carbon dioxide concentration across the mid-Pleistocene transition, Science, 324(5934), 1551-1554, doi:10.1126/science. 1171477

Huybers, P. (2007), Glacial variability over the last two million years: An extended depth-derived agemodel, continuous obliquity pacing, and the Pleistocene progression, Quat. Sci. Rev., 26(1-2), 37-55, doi:10.1016/j.quascirey. 2006.07.013
Imbrie, J., et al. (1992), On the structure and origin of major glaciation cycles. 1. Linear responses to Milankovitch forcing, Paleoceanography, 7, 701-738, doi:10.1029/ 92PA02253.

Imbrie, J., et al. (1993), On the structure and origin of major glaciation cycles: 2 . The 100,000 year cycle, Paleoceanography, 8, 699-735, doi:10.1029/93PA02751.

Jouzel, J., et al. (2007), Orbital and millennial Antarctic climate variability over the past 800,000 years, Science, 317(5839), 793-796, doi:10.1126/science. 1141038 .

Kisakurek, B., A. Eisenhauer, F. Bohm, D. Garbe-Schonberg, and J. Erez (2008), Controls on shell $\mathrm{Mg} / \mathrm{Ca}$ and $\mathrm{Sr} / \mathrm{Ca}$ in cultured planktonic foraminiferan, Globigerinoides $r u$ ber (white), Earth Planet. Sci. Lett., 273(3-4), 260-269, doi:10.1016/j.eps1.2008.06.026.

Koutavas, A., J. Lynch-Stieglitz, T. M. Marchitto, and J. P. Sachs (2002), El Nino-like pattern in ice age tropical Pacific sea surface temperature, Science, 297(5579), 226-230, doi:10.1126/ science.1072376.

Laskar, J., P. Robutel, F. Joutel, M. Gastineau, A. C. M. Correia, and B. Levrard (2004), A long-term numerical solution for the insolation quantities of the Earth, Astron. Astrophys. 428(1), 261-285, doi:10.1051/00046361:20041335.

Lawrence, K. T., Z. H. Liu, and T. D. Herbert (2006), Evolution of the eastern tropical Pacific through Plio-Pleistocene glaciation Science, 312(5770), 79-83, doi:10.1126/ science. 1120395 .

Lea, D. W. (2004), The 100000 -yr cycle in tropical SST, greenhouse forcing, and climate sensitivity, J. Clim., 17(11), 2170-2179, doi:10.1175/15200442(2004)017<2170:TYCITS $>2.0$. CO;2.

LeGrande, A. N., and G. A. Schmidt (2006), Global gridded data set of the oxygen isotopic composition in seawater, Geophys. Res. Lett., 33, L12604, doi:10.1029/2006GL026011.

Lisiecki, L. E., and M. E. Raymo (2005), A Pliocene-Pleistocene stack of 57 globally distributed benthic $\delta^{18} \mathrm{O}$ records, Paleoceanogra phy, 20, PA1003, doi:10.1029/2004PA001071.

Liu, Z., and T. D. Herbert (2004), High-latitude influence on the eastern equatorial Pacific climate in the early Pleistocene epoch, Nature, 427, 720-723, doi:10.1038/nature02338.

Liu, Z. Y., S. I. Shin, B. Otto-Bliesner, J. E. Kutzbach, E. C. Brady, and D. E. Lee (2002), Tropical cooling at the last glacial maximum and extratropical ocean ventilation, Geophys. Res. Lett., 29(10), 1409, doi:10.1029/2001GL013938.

Liu, Z. H., L. C. Cleaveland, and T. D. Herbert (2008), Early onset and origin of 100-kyr cycles in Pleistocene tropical SST records, Earth Planet. Sci. Lett., 265(3-4), 703-715, doi:10.1016/j.epsl.2007.11.016.

Löwemark, L., W. L. Hong, T. F. Yui, and G. W Hung (2005), A test of different factors influencing the isotopic signal of planktonic foraminifera in surface sediments from the northern South China Sea, Mar. Micropaleontol., 55(1-2), 49-62, doi:10.1016/j.marmicro.2005.02.004

Lüthi, D., et al. (2008), High-resolution carbon dioxide concentration record 650,000 
800,000 years before present, Nature, 453, 379-382, doi:10.1038/nature06949.

Marlow, J. R., C. B. Lange, G. Wefer, and A. Rosell-Mele (2000), Upwelling intensification as part of the Pliocene-Pleistocene climate transition, Science, 290(5500), 2288-2291, doi:10.1126/science. 290.5500 .2288

Martinez, J. I. (1994), Late Pleistocene paleoceanography of the Tasman Sea: Implications for the dynamics of the warm pool in the western Pacific, Palaeogeogr. Palaeoclimatol. Palaeoecol., 112(1-2), 19-62, doi:10.1016/ 0031-0182(94)90133-3.

Mathien-Blard, E., and F. Bassinot (2009), Salinity bias on the foraminifera $\mathrm{Mg} / \mathrm{Ca}$ thermometry: Correction procedure and implications for past ocean hydrographic reconstructions, Geochem. Geophys. Geosyst., 10, Q12011, doi:10.1029/2008GC002353.

McConnell, M. C., and R. C. Thunell (2005), Calibration of the planktonic foraminiferal $\mathrm{Mg} / \mathrm{Ca}$ paleothermometer: Sediment trap results from the Guaymas Basin, Gulf of California, Paleoceanography, 20, PA2016, doi:10.1029/2004PA001077.

Medina-Elizalde, M., and D. W. Lea (2005), The mid-Pleistocene transition in the tropical Pacific, Science, 310(5750), 1009-1012, doi:10.1126/science.1115933.

Medina-Elizalde, M., and D. W. Lea (2010), Late Pliocene equatorial Pacific, Paleoceanography, 25, PA2208, doi:10.1029/2009PA001780.

Medina-Elizalde, M., D. W. Lea, and M. S. Fantle (2008), Implications of seawater $\mathrm{Mg}$ / $\mathrm{Ca}$ variability for Plio-Pleistocene tropical climate reconstruction, Earth Planet. Sci. Lett., 269(3-4), 584-594, doi:10.1016/j. eps1.2008.03.014.

Milankovitch, M. (1948), Ausbau und gegenwartiger Stand der astronomischen Theorie der erdgeschichtlichen Klimate, Experientia, 4(11), 413-418, doi:10.1007/BF02144986.

Mudelsee, M., and K. Stattegger (1997), Exploring the structure of the mid-Pleistocene revolution with advanced methods of time-series analysis, Geol. Rundsch., 86, 499-511, doi:10.1007/s005310050157.
Nicet, J. B., and T. Delcroix (2000), ENSOrelated precipitation changes in New Caledonia southwestern tropical Pacific: 1969-98, Mon. Weather Rev., 128(8), 3001-3006, doi:10.1175/1520-0493(2000)128<3001:ERP $\mathrm{CIN}>2.0 . \mathrm{CO} ; 2$

Philander, S. G., and A. V. Fedorov (2003), Role of tropics in changing the response to Milankovich forcing some three million years ago, Paleoceanography, 18(2), 1045, doi:10.1029/ 2002PA000837.

Raymo, M. (1997), The timing of major climate transitions, Paleoceanography, 12, 577-585, doi:10.1029/97PA01169.

Ruddiman, W. F. (2003), Orbital insolation, ice volume, and greenhouse gases, Ouat. Sci. Rev., 22(15-17), 1597-1629, doi:10.1016/ S0277-3791(03)00087-8.

Ruddiman, W. F., M. E. Raymo, D. G. Martinson, B. M. Clement, and J. Backman (1989), Pleistocene evolution: Northern Hemisphere ice sheet and North Atlantic Ocean, Paleoceanography, 4, 353-412, doi:10.1029/PA004i004p00353.

Russon, T., M. Elliot, C. Kissel, G. Cabioch, P. De Deckker, and T. Corrège (2009), Middle-late Pleistocene deep water circulation in the southwest subtropical Pacific, Paleoceanography, 24, PA4205, doi:10.1029/ 2009PA001755.

Russon, T., M. Elliot, A. Sadekov, T. Corrège, G. Cabioch, and P. De Deckker (2010), Interhemispheric asymmetry in the early Pleistocene Pacific warm pool, Geophys. Res. Lett., 37, L11601, doi:10.1029/2010GL043191.

Sadekov, A., S. M. Eggins, P. De Deckker, and D. Kroon (2008), Uncertainties in seawater thermometry deriving from intratest and intert est $\mathrm{Mg} / \mathrm{Ca}$ variability in Globigerinoides ruber Paleoceanography, 23, PA1215, doi:10.1029/ 2007PA001452.

Sarachik, E. S., and M. A. Cane (2010), The ElNino Southern Oscillation Phenomenon, Cambridge Univ. Press, Cambridge, U. K

Shackleton, N. J. (2000), The 100,000-year iceage cycle identified and found to lag temperature, carbon dioxide, and orbital eccentricity,
Science, 289(5486), 1897-1902, doi:10.1126/ science.289.5486.1897.

Sosdian, S., and Y. Rosenthal (2009), Deep-sea temperature and ice volume changes across the Pliocene-Pleistocene climate transitions, Science, 325(5938), 306-310, doi:10.1126 science. 1169938

Steinke, S., H. Y. Chiu, P. S. Yu, C. C. Shen, L. Lowemark, H. S. Mii, and M. T. Chen (2005), $\mathrm{Mg} / \mathrm{Ca}$ ratios of two Globigerinoides ruber (white) morphotypes: Implications for reconstructing past tropical/subtropical surface water conditions, Geochem. Geophys. Geosyst. 6, Q11005, doi:10.1029/2005GC000926.

Stott, L., C. Poulsen, S. Lund, and R. Thunell (2002), Super ENSO and global climate oscillations at millennial time scales, Science, 297(5579), 222-226, doi:10.1126/science. 1071627

Waelbroeck, C., et al. (2009), Constraints on the magnitude and patterns of ocean cooling at the Last Glacial Maximum, Nat. Geosci., 2(2), 127-132, doi:10.1038/ngeo411.

Yu, J., and W. S. Broecker (2010), Comment on "Deep-Sea temperature and ice volume changes across the Pliocene-Pleistocene climate transitions," Science, 328(5985), 1480, doi:10.1126/science.1186544.

G. Cabioch, IPSL/LOCEAN, UMR 7159 IRD CNRS/UPMC/MNHN, Centre IRD d'Ile de France, 32 Ave. Henri Varagnat, F-93143 Bondy CEDEX, France.

T. Corrège, Université de Bordeaux, UMR 5805 EPOC, Avenue des Facultés, F-33405 Talence, France.

P. De Deckker, Research School of Earth Sciences, Australian National University, Canberra, ACT 0200, Australia.

M. Elliot, T. Russon, and A. Sadekov, School of GeoSciences, University of Edinburgh, The King's Buildings, West Mains Road, Edinburgh EH8 9YL, UK. (tom.russon@ed.ac. uk) 